Since the decade of 1940 to the decade of 1950, Mário Pedrosa's writings enhanced the revolutionary importance of the aesthetic dimension. If the connection between art and mass production seemed to accomplish the democratic and socialists objectives in the modern world, the aesthetic dimension was capable to offer to the men the width of the social transformation that it was processed. From the Russian constructivism to the renewed manifestations of the constructive tendency among them, the concretism - sought to aim at the artistic work, inserting its in the collective activity of the society based on the planning of the production. That was the great contribution of the modern art, that it approximated the artists and workers.

Keywords: Mário Pedrosa, constructive project, review socialist vanguard, politics of the arts. 


\section{Política das artes: Mário Pedrosa e a defesa da arte independente}

Marcelo

MARI

A partir de meados da década de 1940 e durante a década de 1950, os escritos de Mário Pedrosa realçaram a importância revolucionária da dimensão estética. Se o reatamento entre arte e produção em massa parecia cumprir anseios democráticos e socializadores no mundo moderno, a dimensão estética era capaz de oferecer aos homens a amplitude da transformação social que se processava. Desde o construtivismo russo até as manifestações mais renovadas da tendência construtiva entre elas, o concretismo - visavam objetivar o trabalho artístico, inserindo-o na atividade coletiva e emancipadora da sociedade baseada no planejamento da produção. Essa foi a grande contribuição da arte moderna, que aproximou o artista do trabalhador.

Palavras chave: Mário Pedrosa, projeto construtivo, revista vanguarda socialista, política das artes. 


\section{O Manifesto por uma arte revolucionária e independente e sua difusão no Brasil}

A partir de meados da década de 1940 e durante a década de 1950, os escritos de Mário Pedrosa realçaram a importância revolucionária da dimensão estética. O construtivismo russo e as manifestações mais renovadas da tendência construtiva - entre elas, o concretismo - visavam objetivar o trabalho artístico, inserindo-o no rol das atividades coletivas da sociedade moderna e baseada no planejamento da produção. Esse novo entendimento do significado da produção artística na sociedade resultou na aproximação entre o artista e o trabalhador.

No entanto, a batalha pela mudança da relação entre arte e política, que fixaria a compreensão da autonomia do campo artístico, foi estabelecida preliminarmente com a disputa intelectual travada entre os defensores dos realismos dominantes, durante os anos de 1930 e 1940, e uma nova via para a produção artística apresentada por Trotski e Breton no famoso Manifesto por uma arte revolucionria independente de 1938.

Em 1942, Pedrosa apresentou sua crítica à arte realista defendida tanto pelas políticas governamentais dos Estados Unidos e do finado Estado Novo no Brasil como pela política cultural do Partido Comunista. Foi, pouco tempo depois, justamente nas páginas do semanário Vanguarda Socialista que se consolidou essa crítica do realismo na arte brasileira e a defesa de uma arte independente 1 . Todos os correligionários do Semanário apostavam em uma via livre dos constrangimentos políticos para as artes. Não somente Pedrosa, mas também Patrícia Galvão e Geraldo Ferraz foram os principais defensores e divulgadores das novas idéias que começavam a circular - no período de abertura democrática do Brasil - nos meios artísticos, intelectuais e oposicionistas. Partindo da defesa cônscia da arte independente, Pedrosa afirmou a necessidade do exercício da liberdade para cumprimento da função geral da arte moderna como promotora de uma nova ordem estética, acompanhada da transformação política e social do Brasil e do mundo. 


\section{Vanguarda Socialista: fim da antinomia entre liberdade e igualdade}

Com a iminente derrota das potências do Eixo na Segunda Guerra Mundial, a base de sustentação da ditadura varguista no Brasil perde força e surgem movimentações políticas em favor da abertura democrática, que foi conquistada com o fim do Estado Novo em 1945. Aproximava-se, para Pedrosa, o momento de regresso do exílio. Depois de ter sido convidado, por Paulo Bittencourt, a fazer reportagens como correspondente internacional e de ter seu visto de partida dos Estados Unidos com destino à Europa negado, Pedrosa decide voltar e estabelecer-se em definitivo no Rio de Janeiro. Ali, ele retoma suas atividades como militante, funda o semanário Vanguarda Socialista e encarrega-se de escrever seus editoriais, torna-se um dos responsáveis pela formação da organização política denominada União Socialista Popular, e também continua seus trabalhos como crítico de arte para o jornal Correio da Manh, no qual dá início a uma seção específica dedicada às artes plásticas em novembro de 1946.

Sem dúvida, o Vanguarda Socialista foi resultado tanto das experiências adquiridas por Pedrosa em sua atividade militante junto ao Workers Party quanto da urgência de se compreender as novas relações conjuntural e estruturalmente estabelecidas no mundo após a Segunda Guerra. Com isso, o Semanário servia de ponto de partida para discussões sobre temas atualíssimos no afã de se constituir um novo marco para o pensamento sobre a estética e sobre a política, sem o erro da incorrência necessária, ou ao dirigismo cultural, ou às teses socialistas estabelecidas pela Terceira Internacional. Portanto, foi mediante essas prerrogativas - de liberdade e de ampliação das fontes tradicionais para a compreensão das novas orientações políticas e artísticas na sociedade - que se formou uma alternativa de intervenção possível para a construção do socialismo frente às experiências de barbárie evidenciadas com o final da Guerra. Nesse momento histórico, política e arte correlacionavam-se e constituíam a base de formação inicial de um projeto estético e político cunhado por Pedrosa para o Brasil.

O Vanguarda Socialista foi organizado e editado por um pequeno grupo formado por Mário Pedrosa, Geraldo Ferraz, Hilcar Leite, Edmundo Muniz e Nelson Veloso, mas seus artigos contavam também com a colaboração de muitos outros intelectuais de 
esquerda, tais como Arnaldo Pedroso D'Horta, Patrícia Galvão e Aristides Lobo; uns formados na tradição marxista e outros não. Eles pretendiam veicular, através do Semanário, idéias avançadas na elaboração de uma via própria para o socialismo, com a crítica da degenerescência do bolchevismo e das práticas equivocadas da social-democracia e com o intuito de organizar um novo movimento político. Donde comenta Pedrosa: "Vanguarda Socialista, como o próprio nome indica, visa fazer a propaganda da idéia socialista e preparar, sem imediatismo ou tempo marcado, quadros para o futuro. Não é órgão de nenhum partido, não está sujeita a nenhuma disciplina partidária; é um trabalho coletivo de vários companheiros irmanados por um mesmo ideal e mais ou menos estruturados pela mesma base cultural marxista." ${ }^{2}$

O processo crítico, pautado em um dinamismo de desvencilhamento seja das verdades estabelecidas seja do credo político dominante, foi levado às últimas conseqüências na revisão dos conceitos elaborados pela doutrina marxista da U.R.S.S. estalinista, pelo movimento trotskista e também no que concerne aos temas mais caros da Segunda Internacional, com o intuito de explicar os acontecimentos que abalaram a humanidade desde os princípios do século XX até os alvores da Guerra Fria. Diz Pedrosa: "Não olharemos para nenhum desses acontecimentos com olhos apologéticos. Não aceitaremos nenhuma ideologia, muito menos as oficiais, como explicação desses grandes acontecimentos." ${ }^{3}$. Entre eles, a Revolução Russa tornara-se um caso exemplar na elaboração de uma alternativa socialista. Tratava-se de reivindicar uma análise objetiva dos acontecimentos, levando em conta o materialismo histórico e, por conseguinte, a separação crítica entre condição econômica e ideologia, tal como foi enunciada por Marx e Lênin, para que se pudesse esclarecer o que foi ditado, no caso da Rússia, "pela necessidade objetiva e o que é conjuntural ou deformação evitável."

Na política, instaurava-se uma equação, entre análise crítica e prejuízo ideológico, capaz de explicar o processo econômico como fator decisivo na construção socialista. O que estava em jogo, segundo Pedrosa nas diretivas do semanário Vanguarda Socialista, era mostrar que não havia ocorrido uma transformação efetiva da base econômica no caso da Revolução Russa - o que negava a 
tese de Trotski sobre a nacionalização e o coletivismo da produção como fator fundamental para a distribuição igualitária do produto social. Daí entendia-se a fraqueza da análise trotskista diante da concentração do poder econômico no regime soviético. Esse poder foi então acompanhado pela passagem da igualdade econômica como finalidade última da transformação política para a situação de suporte ideológico para a estabilização política do regime. Por sua vez, essa justificação ideológica da garantia progressiva de igualdade econômica servia, no recrudescimento das práticas sociais, como legitimação da ditadura e adiamento histórico da necessidade de igualdade política e da liberdade.

Mário Pedrosa foi enfático, na conclusão do editorial, sobre a relação intrínseca entre liberdade e edificação socialista: "Nosso esforço não é ambicioso; pois não é isolado. Por toda parte na Europa como na América [...], ele se vai registrando numa elaboração vagarosa mas constante, porque não passa do processo do próprio pensamento marxista que, na volta às suas origens, quer renovar-se ao calor das formidáveis transformações de nossa época. Do fundo de suas pesquisas, estamos certos de uma coisa: é de que a liberdade não soçobrará para que o socialismo triunfe, pois, sem ela, o socialismo jamais será possível." ${ }^{5}$

A opção pela liberdade é fundamental análise de Mário Pedrosa, visto que a mudança da estrutura econômica da sociedade não era único elemento necessário na via da transformação social. Se, no princípio de sua produção intelectual, havia condição para se acreditar que a nova arte só viria com a revolução política completa e com a modificação das relações de produção, agora e por causa dos acontecimentos prementes da época - derivados em grande parte do erro interpretativo implementado pelo comunismo russo -, Pedrosa apostava muito mais na necessidade de manter tanto quanto possível os princípios integrados de liberdade e de igualdade econômica e política, colaborando para a mesma finalidade. De um lado, nos Estados Unidos ocorria uma institucionalização da liberdade em benefício de interesses econômicos socialmente obscurecidos, de outro, na URSS, a supressão completa da liberdade em favor da prerrogativa econômica. Não poderia haver antagonismo entre esses princípios, a igualdade econômica não vingaria em detrimento da igualdade política e da liberdade, e vice-versa. Por isso também, 
a conscientização dos movimentos sociais e das organizações de trabalhadores era fator decisivo ${ }^{6}$.

$\mathrm{Na}$ arte, o que mudou na análise crítica de Pedrosa a partir de sua volta ao Brasil em 1945, com a passagem do interesse pelas gravuras de Käthe Kollwitz para o abstracionismo, foi a ênfase depositada no exercício da liberdade na arte e na luta pela formação de consciência. Se Pedrosa, impressionado com o avanço das forças sociais regressivas, considerou necessário, em seu ensaio sobre Kollwitz, que a arte conscientizasse o homem da ideologia espraiada pelo fascismo e tomasse partido na luta de classes vigente na sociedade cindida, agora o problema era de natureza mais complexa e dizia respeito à batalha não somente contra o caráter ideológico do comunismo, mas à toda forma de coisificação e adestramento do próprio homem, que servia a objetivos utilitários; razões do Estado e, por conseguinte, da classe dominante.

\section{Arte moderna e política: reivindicação de independência para a arte}

Mário Pedrosa retoma a questão da liberdade no ensaio "A arte e os políticos", publicado no jornal Tribuna da Imprensa em 25-10-1952 - que discute a significação da arte moderna e seus pontos de contato com a política ${ }^{7}$. Nele, liberdade e ação consciente são essenciais para uma transformação social profunda, sem as quais toda prática humana estaria ameaçada. É preciso dizer que o anseio manifesto pela liberdade no semanário Vanguarda Socialista, como fator decisivo na mutação das relações de classe e das práticas sociais, surgia em Pedrosa através do interesse pelas atividades desinteressadas do espírito. Essa prerrogativa da noção de descondicionamento dos processos criativos era fonte para um desenvolvimento da análise crítica-objetiva, que visava não apenas a negação das visões de mundo subordinadas à prática social em vigor mas também a construção de um projeto alternativo de civilização. Por conseguinte, se o interesse de Pedrosa pela liberdade embebiase nas proposições inabaláveis de Rosa Luxemburgo, o combate pungente do processo falso de conhecimento encontrava identidade com o pensamento de Karl Manheim, quando esse fez a crítica da 
relação degenerativa entre pensamento e a prática estabelecida nos regimes totalitários.

Não era para menos, tanto o fortalecimento da atuação independente dos Estados e dos poderes públicos recém constituídos no Pós-Guerra quanto a pulverização das ações coletivas em simples ações individuais tornavam necessária a defesa da democracia para a resistência contra impulsos sociais destrutivos. Cada vez mais, a igualdade política e a liberdade eram encaradas como valores sem os quais nem a arte nem qualquer outra ação consciente poderiam sobreviver. Toda fonte de distorção ou integração condicionada da atividade crítica deveria ser denunciada. Pedrosa considerava necessário assegurar na vida contemporânea, o exercício da liberdade, o desenvolvimento "das atividades desinteressadas do espírito [...] numa época de tarado utilitarismo", e continua, "o espírito criador, a verdadeira cultura não florescem senão num clima de liberdade. Sob as tiranias, é claro, os gênios não desaparecem. Ao contrário, muitas vezes irrompem - pela fatalidade mesma de ter de vencer resistências obscurantistas $[\ldots]$, mas só na liberdade, na democracia, os frutos solitários do gênio permanecem, frutificam e se socializam."

Ainda que os artistas e suas grandes obras nasçam tanto nos regimes tirânicos como na democracia, apenas nessa seria possível um aprimoramento estético em sentido social. Tão somente, com liberdade e democracia, a realização dos desígnios mais recônditos do mundo artístico poderia ser difundida e intensificar a troca imprescindível entre os aspectos individuais e coletivos da experiência humana. Todas as atividades desinteressadas do espírito proporcionavam, pelo desenvolvimento independente dos condicionamentos sociais, uma superação das práticas humanas estabelecidas. Na sociedade contemporânea, travava-se o embate enérgico entre uma nova forma de conhecimento baseada na percepção e uma racionalidade operativa e condicionada. Uma, acompanhava com exclusividade as exigências materiais - assegurando a permanência e o aperfeiçoamento do poder da esfera pública ou do Estado sobre os indivíduos -, outra, sustentava a superação do mecanicismo social pela ação da consciência.

O exercício da liberdade era condição prévia para que o espírito criador ou a consciência formadora atuassem no sentido de estabelecer não menos uma sensibilidade renovadora que relações sociais inéditas. Donde Mário Pedrosa assevera, em objeção tanto 
ao vigor destrutivo da institucionalização como à incapacidade dos regimes totalitários, "a superioridade democrática (que) consiste em criar o clima espiritual mais capaz de dar estrutura, forma e estilo às grandes culturas, às culturas autênticas que marcam os povos com fisionomia própria ou dão a todos os estágios de civilização, mesmo os mais primitivos, o privilégio de sobreviver os milênios" ${ }^{\prime \prime}$. Contra o mecanicismo sócio-econômico, uma defesa possível consistia em manter o avanço das atividades livres não apenas para denunciar a subordinação do homem às determinações históricas do capitalismo e a incapacidade de controle e de direcionamento racional nos regimes políticos vigentes, mas também para insuflar vida no esquema de relações sociais quase inanimadas a fim de que se iniciasse um processo construtivo de uma nova sociedade.

Nessas condições inauditas, cabia ao homem criar formações ou estruturas culturais in-gerentes - baseadas nas condições favoráveis da democracia e da liberdade - para uma mutação substancial do mundo e, com isso, evitar a prevalência do utilitarismo afeito à lógica da relação entre coisas, próprio de um racionalismo frio e eficiente que se tornava em último termo ameaçador à vida. Sua conservação significava ainda mais tanto uma progressiva anulação do homem, obstruindo sua consciência formadora, como uma distorção de sua apreensão objetiva. Assim, a política devia passar por uma revisão de seus objetivos e a conscientização das classes trabalhadoras seria o primado de uma nova política feita a partir de baixo. Explica Pedrosa: "A política em nossos dias tende a tornar-se cada vez mais uma técnica e muito menos um combate pela elevação material e cultural do povo. Os poderes públicos à medida que crescem, que intervêm por toda parte, que abarcam todos os aspectos da vida moderna se vão tornando monstros irresponsáveis de mil cabeças, movidos apenas por uma norma - a da eficiência" ${ }^{10}$.

\section{A função transformadora da arte moderna}

Em contraposição a toda prática social, que visava à máxima concretização de objetivos produtivos em benefício das classes ou dos grupos dominantes, as atividades livres encontravam-se dissociadas das relações sociais estabelecidas e seriam o fator experimental 
necessário de superação do viés exclusivamente econômico na formação de uma nova sociedade para além das manifestações empobrecidas da experiência humana. Por sua vez, as atividades livres renunciavam a todo aperfeiçoamento do mecanicismo social que aumentasse a subordinação humana aos interesses do lucro, que de forma infalível enfeixavam as rotas possíveis de atuação, restringindo-as na política ou na economia.

Entre essas atividades, a arte tinha função essencial no processo reeducador do homem pela ampliação de sua sensibilidade embrutecida, o que demandava uma superação das restrições impostas pelos Estados livres e pelos entraves materiais e espirituais em favor da consciência para a emancipação. Segundo Pedrosa, a arte podia romper com esse ciclo de produção e reprodução da sociedade: "Contra esse novo Frankenstein, o homem é sem defesa. Ou por outra, sua defesa consiste em estimular as atividades desinteressadas, mesmo as atividades pueris. No campo dessas atividades, a de força resistente maior é sem dúvida a arte moderna." 11

Se antes do advento das vanguardas artísticas havia um assenti-mento com a ordem instituída e um limite para se reproduzir cenas históricas, alegóricas e mitológicas ou retratos de personalidades do meio social, agora tocava às artes plásticas - em sua resistência à incorporação nas práticas sociais estabelecidas uma função mais nobre: cultivar uma nova percepção da realidade e incentivar todo tipo de experiência capaz de não se limitar pelas estruturas mentais do dia-a-dia. Conclui Pedrosa: "Para Mondrian, para Groupius, a única salvação do homem em face da máquina, está em reeducá-lo esteticamente. Em fazê-lo parar sua corrida sem sentido, em sua afobação cotidiana, para que contemple, se detenha não apenas diante de um quadro, de uma escultura ou de um monumento, mas também diante dos humildes objetos que o envolvem, atento a que as coisas sirvam naturalmente aos fins a que se destinam, as formas sejam adequadas às funções e a ordem derive da sincronização da imaginação com a necessidade." ${ }^{12}$

A procura pela expressão justa, por parte de Mário Pedrosa, entre função e forma indicava a realização de um ideal de transparência na compreensão e na ordenação do mundo, que evitava o desvinculo das condições e motivações reais de produção 
e reprodução social e propiciavam a construção de outro modo de vida. Evitava-se com isso, a insuficiência do plano único da ação para resolver as novas dinâmicas engendradas pela instituição de valores sociais atinentes à manutenção das estruturas de poder. Essa dimensão da nova consciência pautada no valor de uso deveria ser posta à prova sob pena de ineficácia da ação transformadora. Revelar o vínculo existente entre pensamento e prática social estabelecida era sinal de um processo crítico que se completava em duas direções e também da importância atribuída às atividades livres, diante da ação e do pensamento condicionados à ordem vigente. Nesse sentido, a arte moderna negou os preceitos acadêmicos do século XIX e a velha dinâmica entre forma e conteúdo da obra para afastar a influência verbal ou literária predominante.

Para Pedrosa, a arte moderna era expressão da adequação perfeita entre espírito e matéria. Essa adequação trazia de volta à razão um significado mais amplo, derivado da ênfase na experiência humana e na qual se restabelecia o contato com o mundo; com isso, far-se-ia o coroamento da estética, que sensibilizaria a razão. Se a experiência humana empobrecida reafirmava na mesma medida as versões mais simplificativas sobre a validade e a predominância do postulado pragmático, era preciso revelar - e por que não através da evidente formação de consciência pela arte? - quanto existia de falso na exigência prática e a serviço de quem ela se encontrava. Assim, o momento da consciência tornava-se a passagem tanto do fetichismo para o valor de uso como da aparente organização racional do mundo para uma unidade verdadeira entre arte e mundo. Não se tratava aqui de um problema supérfluo ou ligado em demasia a uma teoria do valor, mas da tentativa de levar transparência para as dicotomias forjadas entre homem e mundo, razão e experiência.

A arte moderna convertia-se na negação da relação obscurecida entre entendimento e sensibilidade ou no momento de consciência, que não se deixava lograr pelo antagonismo entre imaginação e necessidade, para que fosse possível uma ação cônscia na construção de um projeto civilizatório renovador. Da arte e das atividades livres tinha-se, ao contrário do que pudesse supor, um ponto de vista crítico-objetivo novo e uma alternativa 
eficaz para superação da ordem e do poder vigentes. Decorre disso, que Pedrosa indicava a conquista de uma razão sensível como base de onde partiria a função emancipadora da arte, e sem a qual tanto o entendimento como a ação estavam condenados a uma separação nociva: "Desde Marx e Rimbaud, a realidade e a poesia ou se fundem ou o mundo entra em caos. Não é possível a dicotomia entre ação, domínio por excelência da política e o pensamento, que abrange desde as intuições mais abstrusas da matemática moderna às criações mais abstratas de um Klee ou de um Max Bill. Os políticos de nossos dias ou concorrem para uma harmonia ou estão trabalhando para fazer saltar o mundo que pretendem estar dirigindo, em mil pedaços, num desses dias.." ${ }^{13}$

A tarefa da arte moderna inscrevia-se na transformação profunda da sensibilidade do homeme, por isso, também implicava uma alteração da visão de mundo consolidada e da relação cognitiva recrudescida. Tratava-se de apostar na revolução interna proporcionada pela arte e no aprimoramento pleno de um novo processo cognitivo sob sua égide contra o racionalismo abstrato da sociedade burguesa.

Em um de seus depoimentos na década de setenta, Pedrosa comentaria: "A "arte moderna" ia mostrar-se assim mais do que uma simples moda ou escola, como qualquer das inúmeras que passaram pela história contemporânea (e incluindo-se nesta a art nouveau e ampliando-se também o rococ e o neoclássico), um movimento cultural da maior transcendência. Primeiro que tudo vinha revelar o que se havia esquecido no curso do desenvolvimento da civilização burguesa, de seu racionalismo abstrato, conseqüente à supremacia da economia capitalista com suas relações de produção fundadas no mercado, onde as coisas perdem a realidade concreta, e transferidas ao plano das superestruturas em escala mundial: que a Arte em nenhum momento da evolução humana foi monopólio ou produto direto dos progressos econômicos e intelectualistas. Foi, entretanto, em nome dessa supremacia econômica e política e dos conhecimentos que adquiriam sistematicamente reduzidos a normas lógicas esvaziadas de seu conteúdo contraditório, que as burguesias nacionais européias passaram a proclamar ter também a supremacia e o monopólio da "grande" arte, das "belas-artes", desde o advento do chamado milagre grego, em que querem encontrar suas origens ou seu modelo." 14 
Contra esse estado miserável da civilização burguesa é que a arte moderna se insurgira. Ela lutava contra a manutenção de uma ordem social fundada no descrédito da experiência direta e estreita entre homem e mundo, contra os preconceitos intelectualistas baseados na pretensão ideológica de onisciência do indivíduo burguês autocentrado e, em suma, contra a sociedade de mercado em que tudo deveria ser redutível aos parâmetros da prática ou à moral do utilitarismo.

Pedrosa aponta a dialética cultural inscrita na arte moderna: "No entanto, por uma dessas reviravoltas dialéticas da história, a própria expansão imperialista que se inicia pelo fim do século vai abrir à arte ocidental o contato com as culturas dos povos primitivos, ainda em estágios tribais, comunitários ou précapitalistas. Desse contato é que, se não nasce, desenvolvese o que será a "arte moderna". O impacto desse contato foi tremendo sobre as Ciências Sociais, da Sociologia à Antropologia, à Etnografia, à Psicologia Social que até então se desenrolavam independentemente das investigações de campo, por analogias e deduções conforme a lógica formal, de natureza idealista ou mistificadora, ou por algumas induções e intuições geniais isoladas de seus sábios. [...] A idéia da superioridade branca sobre os outros povos da periferia econômica e cultural começava a ser batida em brecha pelo próprio desenvolvimento das Ciências Sociais e culturais na época imperialista. A arte moderna é em grande parte resultante dessa dialética cultural. Assim, ao mesmo tempo em que o imperialismo conquista, explora e destrói as economias, o viver e as culturas autóctones desses povos "bárbaros", a arte que se começa a fazer no ocidente vai enriquecer-se com a contribuição das forças culturais até então insuspeitas desses mesmos povos"15.

Para Pedrosa, a arte moderna nascia da contradição que se instaurava entre a tradição ossificada da cultura européia e as descobertas - feitas por antropólogos, etnólogos, psicólogos, etc. durante a expansão capitalista da Europa em busca de novos mercados - de formas expressivas e impactantes realizadas pelas culturas dos povos ditos "primitivos". Neles, a valorização das experiências perceptivas e do caráter fisionômico dos objetos revelava uma relação mais próxima entre sujeito e objeto em franca oposição ao conhecimento instrumental do homem moderno. Cabia à arte moderna realizar uma 


\section{mutação profunda da sensibilidade e da compreensão consolidadas pelo pensamento etnocêntrico, enquanto ocorria a transformação da base econômica e social dos ditos povos "primitivos" ou periféricos.}

\section{Notas}

1. O Manifesto por uma arte revolucionária e independente de Trotsky e Breton foi publicado pela primeira vez e integralmente no Brasil no semanário Vanguarda Socialista em 1946.

2. PEDROSA, M. Diretivas In Vanguarda Socialista, Rio de Janeiro, ano I, $n^{\circ} 1,31$ de agosto de 1945, (frontispício).

3. Idem, ibidem, (frontispício).

4. Idem, ibidem, (frontispício).

5. Cf. LOUREIRO, I. M. Vanguarda socialista (1945-1948): um episódio do ecletismo na história do marxismo brasileiro. Dissertação de mestrado apresentada ao Departamento de Filosofia da Faculdade de Filosofia, Letras e Ciências Humanas da USP, São Paulo, 1984. Profa. Orientadora Marilena Chauí.

6. PEDROSA, M. Diretivas In Vanguarda Socialista, Rio de Janeiro, ano I, $\mathrm{n}^{\circ} 1,31$ de agosto de 1945, p. 04.

7. PEDROSA, M. A arte e os políticos In Tribuna da Imprensa, Rio de Janeiro, 25 de outubro de 1952, p. 08. Aqui, a análise de Pedrosa aparenta-se muito com as definições apresentadas por Karl Manheim ao problema ético da liberdade em nosso tempo. Como veremos, esse interesse pela separação entre processo consciente ou ideológico na interpretação da sociedade remonta a um escrutínio, feito por Pedrosa, sobre o fundamento das relações entre pensamento e matéria, em grande parte derivado de sua concepção da Gestalt aplicada à arte.

8. PEDROSA, M. A arte e os políticos In Tribuna da Imprensa, Rio de Janeiro, 25 de outubro de 1952, p. 08.

9. Idem, ibidem. p. 08. (parênteses nossos).

10. Idem, ibidem, p. 08.

11. Idem, ibidem, p. 08.

12. Idem, ibidem, p. 08.

13. PEDROSA, M. A arte e os políticos In Tribuna da Imprensa, Rio de Janeiro, 25 de outubro de 1952, p. 08.

14. PEDROSA, M. Às vésperas da Bienal In Homem, mundo, arte em crise. São Paulo: Editora Perspectiva, 1986, p. 285.

15. PEDROSA, M. Às vésperas da Bienal In Homem, mundo, arte em crise. São Paulo: Editora Perspectiva, 1986, pp. 285-6.

\section{Referências}

KOFFKA, K. Teoria de la estructura: la psicologia novísima. Madrid: Ediciones de la Lectura, s. d. 
LOUREIRO, I. M. Vanguarda socialista (1945-1948): um episódio do ecletismo na história do marxismo brasileiro. Dissertação de mestrado apresentada ao Departamento de Filosofia da Faculdade de Filosofia, Letras e Ciências Humanas da USP, São Paulo, 1984. Profa. Orientadora Marilena Chauí.

MANNHEIM, K. Ideologia e utopia. Rio de Janeiro: Zahar Editores, 1976.

PEDROSA, M. Homem, mundo, arte em crise. So Paulo: Editora Perspectiva, 1986.

PEDROSA, M. Tribuna da Imprensa, Rio de Janeiro, 25 de outubro de 1952, p. 08.

PEDROSA, M. Vanguarda Socialista, Rio de Janeiro, ano I, $\mathrm{n}^{\circ}$ 1, 31 de agosto de 1945. 
Política das artes: Mário Pedrosa e a defesa da arte independente

\section{Marcelo Mari}

Possui doutorado em Filosofia pela FFLCH-USP (2006). Atualmente é Professor da FAV-UFG. Pesquisa os seguintes temas: arte e sociedade, arte moderna, concretismo, crítica de arte, Mário Pedrosa, realismo, filosofia e estética.

E-mail: arte1960@yahoo.com 